\title{
Relationship between plasma high mobility group box-1 protein levels and clinical outcomes of aneurysmal subarachnoid hemorrhage
}

\author{
Xiang-Dong Zhu*, Jing-Sen Chen, Feng Zhou, Qi-Chang Liu, Gao Chen and Jian-Min Zhang
}

\begin{abstract}
Background: High-mobility group box 1 (HMGB1), originally described as a nuclear protein that binds to and modifies DNA, is now regarded as a central mediator of inflammation by acting as a cytokine. However, the association of HMGB1 in the peripheral blood with disease outcome and cerebrovasospasm has not been examined in patients with aneurysmal subarachnoid hemorrhage.
\end{abstract}

Methods: In this study, 303 consecutive patients were included. Upon admission, plasma HMGB1 levels were measured by ELISA. The end points were mortality after 1 year, in-hospital mortality, cerebrovasospasm and poor functional outcome (Glasgow Outcome Scale score of 1 to 3) after 1 year.

Results: Upon admission, the plasma HMGB1 level in patients was statistically significantly higher than that in healthy controls. A multivariate analysis showed that the plasma HMGB1 level was an independent predictor of poor functional outcome and mortality after 1 year, in-hospital mortality and cerebrovasospasm. A receiver operating characteristic curve showed that plasma HMGB1 level on admission statistically significantly predicted poor functional outcome and mortality after 1 year, in-hospital mortality and cerebrovasospasm of patients. The area under the curve of the HMGB1 concentration was similar to those of World Federation of Neurological Surgeons (WFNS) score and modified Fisher score for the prediction of poor functional outcome and mortality after 1 year, and in-hospital mortality, but not for the prediction of cerebrovasospasm. In a combined logistic-regression model, HMGB1 improved the area under the curve of WFNS score and modified Fisher score for the prediction of poor functional outcome after 1 year, but not for the prediction of mortality after 1 year, in-hospital mortality, or cerebrovasospasm.

Conclusions: HMGB1 level is a useful, complementary tool to predict functional outcome and mortality after aneurysmal subarachnoid hemorrhage. However, HMGB1 determination does not add to the accuracy of prediction of the clinical outcomes.

Keywords: Aneurysmal subarachnoid hemorrhage, Cerebrovasospasm, Functional outcome, High-mobility group box 1, Mortality

*Correspondence: hzzhuxiangdong@163.com

Department of Neurosurgery, The Second Affiliated Hospital, School of

Medicine, Zhejiang University, 88 Jiefang Road, Hangzhou 310000, PR China 


\section{Background}

Subarachnoid hemorrhage (SAH) following cerebral aneurysm rupture is associated with high rates of morbidity and mortality [1]. Early prognostication of the risk of death or of a poor long-term outcome would enable optimized care and improved allocation of health-care resources. Several scales of outcome prediction, including the World Federation of Neurological Surgeons (WFNS) score [2] and Fisher score [3], are known to be associated with poor clinical outcomes. However, a readily measurable predictive marker predicting clinical outcomes in patients with SAH would be helpful for early prognostication and risk stratification, and is attracting increasing attention as a potential predictor of outcome in $\mathrm{SAH}[4]$.

High-mobility group box 1 (HMGB1) is constitutively expressed in the nuclei of eukaryotic cells. It belongs to a family of high mobility group nuclear proteins that were described in the 1970s as gene regulators that bind to and change the configuration of DNA [5,6]. It later became evident that HMGB1 is actively secreted from cells, has cytokine activities and is a late mediator of endotoxin lethality in mice [7]. Passive release of HMGB1 from necrotic cells also triggers inflammation [8]. Receptors for HMGB1 signaling include receptors for advanced glycation end-products and Toll-like receptors. HMGB1 is a central actor in the inflammatory network because it is induced by a number of cytokines and itself induces a series of inflammatory reactions [9-12].

HMGB1 is widely expressed in various tissues, including the brain [13-15]. The local extracellular accumulation of this cytokine in the brain, as a result of its intracerebroventricular administration or its release from dying neurons during cerebral ischemia, elicits local inflammatory events in mice [16-18]. Moreover, HMGB1 also promotes neuroinflammation in postischemic rat brain [17] and in the neurodegenerative processes associated with Alzheimer's disease [19,20]. Taken together, HMGB1 behaves as a typical immunoregulatory cytokine by promoting astrocyte activation and thus the production of a potent mixture of bioactive protein factors involved in inflammatory/immune responses in the brain [21].

HMGB1 is increased in the cerebrospinal fluid from meningitis patients [22] and in the serum of cerebral ischemia patients [23]. Recent data have identified HMGB1 in the cerebrospinal fluid as a potential biomarker of neurological outcome following SAH in humans [24,25], suggesting HMGB1 may represent a marker of neurological injury. However, no published information exists to date about the association between HMGB1 in the peripheral blood and disease outcome and cerebrovasospasm after SAH. The present study aimed to investigate the ability of plasma HMGB1 to

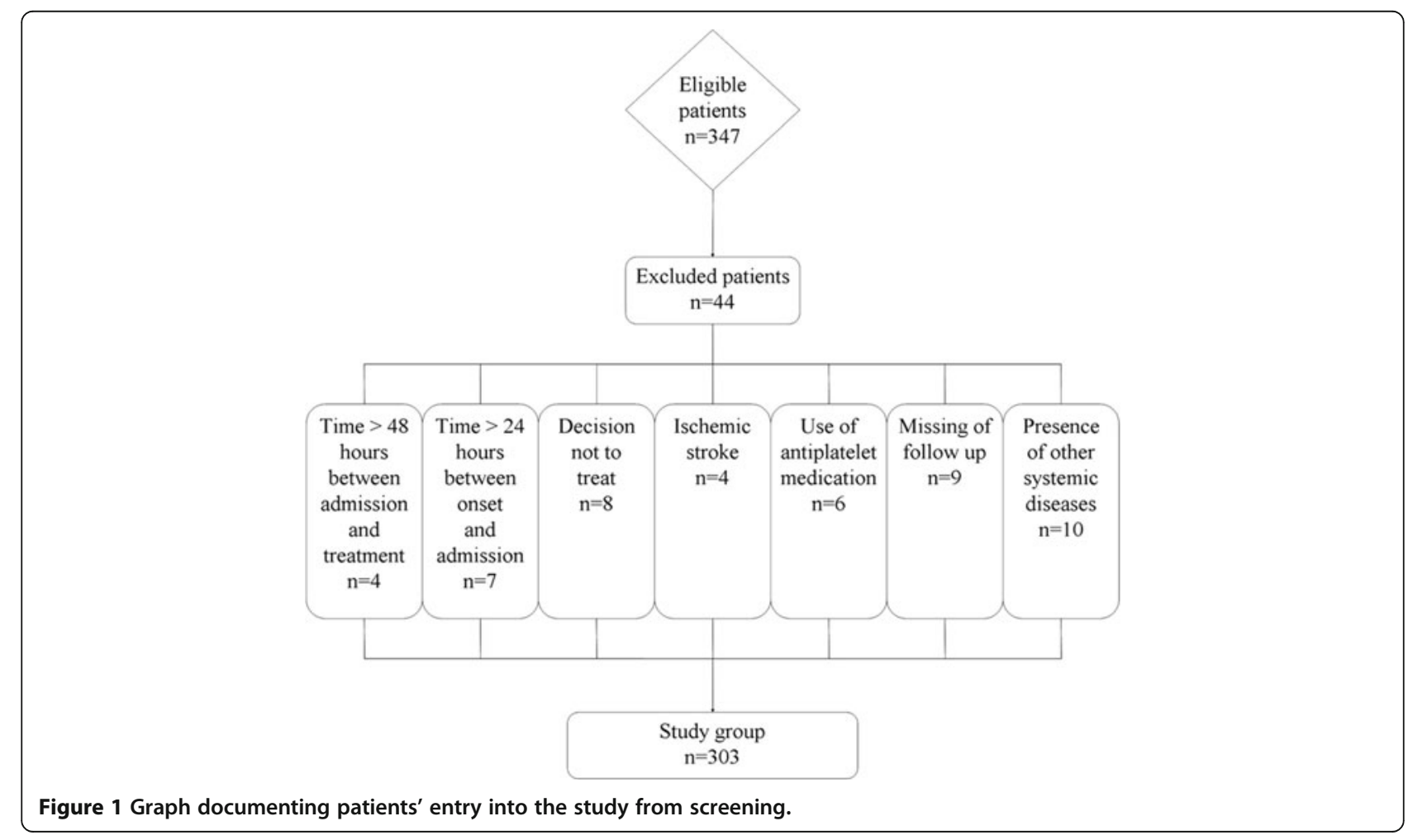


Table 1 The characteristics for 303 patients

\begin{tabular}{|c|c|}
\hline Characteristic & \\
\hline Sex (male/female) & $131 / 172$ \\
\hline Age (years) & $43.9 \pm 12.4$ \\
\hline $\begin{array}{l}\text { World Federation of Neurological } \\
\text { Surgeons score on admission }\end{array}$ & $2.3 \pm 1.2$ \\
\hline Modified Fisher score on admission & $2.7 \pm 1.0$ \\
\hline \multicolumn{2}{|l|}{ Aneurysmal location } \\
\hline Posterior communication artery & $83(27.4 \%)$ \\
\hline Internal carotid artery & $43(14.2 \%)$ \\
\hline Anterior communication artery & $66(21.8 \%)$ \\
\hline Middle cerebral artery & $45(14.9 \%)$ \\
\hline Anterior cerebral artery & $35(11.6 \%)$ \\
\hline Posterior cerebral artery & $23(7.6 \%)$ \\
\hline Vertebral artery & $8(2.6 \%)$ \\
\hline Surgery & $186(61.4 \%)$ \\
\hline Aneurysmal size (mm) & $7.2 \pm 4.9$ \\
\hline Rebleeding & $16(5.3 \%)$ \\
\hline Acute hydrocephalus & $90(29.7 \%)$ \\
\hline Intracerebral hemorrhage & $39(12.9 \%)$ \\
\hline Intraventricular hemorrhage & $72(23.8 \%)$ \\
\hline External ventricular drain & $109(36.0 \%)$ \\
\hline Angiographic vasospasm & $131(43.2 \%)$ \\
\hline Computed tomography ischemia & $50(16.5 \%)$ \\
\hline Admission time (hours) & $4.7 \pm 3.6$ \\
\hline Plasma-sampling time (hours) & $6.7 \pm 4.4$ \\
\hline Seizure & $44(14.5 \%)$ \\
\hline Plasma C-reactive protein level (mg/L) & $7.1 \pm 2.7$ \\
\hline plasma D-dimer level (mg/L) & $2.1 \pm 0.9$ \\
\hline Plasma HMGB1 level (ng/mL) & $8.5 \pm 3.6$ \\
\hline
\end{tabular}

Numerical variables were presented as mean \pm standard deviation. Categorical variables were expressed as counts (percentage). HMGB1, high mobility group box-1.

predict the disease outcome and cerebrovasospasm in patients with aneurysmal SAH.

\section{Subjects and methods \\ Study population}

Between July 2008 and March 2010, all patients with aneurysmal SAH confirmed by computerized tomography $(\mathrm{CT})$ angiography with or without digital subtraction angiography who were admitted to the Department of Neurosurgery, Second Affiliated Hospital, School of Medicine, Zhejiang University were evaluated in the study. Inclusion criteria were clinical history of SAH within the last 24 hours before admission and the treatment by surgery or coiling within the 48 hours after admission. Exclusion criteria were age less than 18 years, existing previous head trauma, neurological diseases including ischemic or hemorrhagic stroke, use of antiplatelet or anticoagulant medication, and presence of other prior systemic diseases including uremia, liver cirrhosis, malignancy, chronic heart or lung disease, diabetes mellitus and hypertension.

A control group consisted of 150 healthy subjects without existing previous head trauma, neurological diseases including ischemic or hemorrhagic stroke, use of antiplatelet or anticoagulant medication, and presence of other prior systemic diseases including uremia, liver cirrhosis, malignancy, chronic heart or lung disease, diabetes mellitus and hypertension.

Table 2 The factors associated with 1-year mortality

\begin{tabular}{|c|c|c|c|}
\hline & Non-survivors & Survivors & $P$ value \\
\hline & $(n=42)$ & $(n=261)$ & \\
\hline Sex (male/female) & $18 / 24$ & $113 / 148$ & 0.958 \\
\hline Age (years) & $45.4 \pm 13.4$ & $43.6 \pm 12.2$ & 0.389 \\
\hline WFNS score on admission & $4.0 \pm 0.7$ & $2.1 \pm 1.0$ & $<0.001$ \\
\hline $\begin{array}{l}\text { Modified Fisher score } \\
\text { on admission }\end{array}$ & $4.2 \pm 0.6$ & $2.5 \pm 0.8$ & $<0.001$ \\
\hline Aneurysmal location & & & 0.614 \\
\hline Posterior communication artery & $8(19.0 \%)$ & 75 (28.7\%) & \\
\hline Internal carotid artery & $6(14.3 \%)$ & $37(14.2 \%)$ & \\
\hline Anterior communication artery & $9(21.4 \%)$ & $57(21.8 \%)$ & \\
\hline Middle cerebral artery & $7(16.7 \%)$ & $38(14.6 \%)$ & \\
\hline Anterior cerebral artery & $6(14.3 \%)$ & 29 (11.1\%) & \\
\hline Posterior cerebral artery & $4(9.5 \%)$ & $19(7.3 \%)$ & \\
\hline Vertebral artery & $2(4.8 \%)$ & $6(2.3 \%)$ & \\
\hline Surgery & $21(50.0 \%)$ & $165(63.2 \%)$ & 0.102 \\
\hline Aneurysmal size (mm) & $11.1 \pm 5.3$ & $6.6 \pm 4.5$ & $<0.001$ \\
\hline Rebleeding & $10(23.8 \%)$ & $6(2.3 \%)$ & $<0.001$ \\
\hline Acute hydrocephalus & $25(59.5 \%)$ & 65 (24.9\%) & 0.001 \\
\hline Intracerebral hemorrhage & 19 (45.2\%) & $20(7.7 \%)$ & $<0.001$ \\
\hline Intraventricular hemorrhage & 37 (88.1\%) & 35 (13.4\%) & $<0.001$ \\
\hline External ventricular drain & $38(90.5 \%)$ & $71(27.2 \%)$ & $<0.001$ \\
\hline Angiographic vasospasm & $38(90.5 \%)$ & $93(35.6 \%)$ & $<0.001$ \\
\hline Computed tomography ischemia & $18(42.9 \%)$ & $32(12.3 \%)$ & $<0.001$ \\
\hline Admission time (hours) & $5.5 \pm 4.4$ & $4.6 \pm 3.5$ & 0.128 \\
\hline Seizure & $9(21.4 \%)$ & 35 (13.4\%) & 0.171 \\
\hline $\begin{array}{l}\text { Plasma C-reactive protein } \\
\text { level (mg/L) }\end{array}$ & $8.7 \pm 3.3$ & $6.9 \pm 2.6$ & $<0.001$ \\
\hline plasma D-dimer level (mg/L) & $2.4 \pm 1.0$ & $2.0 \pm 1.0$ & 0.015 \\
\hline Plasma HMGB1 level (ng/mL) & $12.7 \pm 3.2$ & $7.9 \pm 3.2$ & $<0.001$ \\
\hline
\end{tabular}

Numerical variables are presented as mean \pm standard deviation. Categorical variables are expressed as counts (percentage). Numerical variables were analyzed by Mann-Whitney U-test or unpaired Student $t$ test. Categorical variables were analyzed by chi-square test or Fisher exact test. HMGB1, high mobility group box-1; n, number of patients; WFNS, World Federation of Neurological Surgeons. 

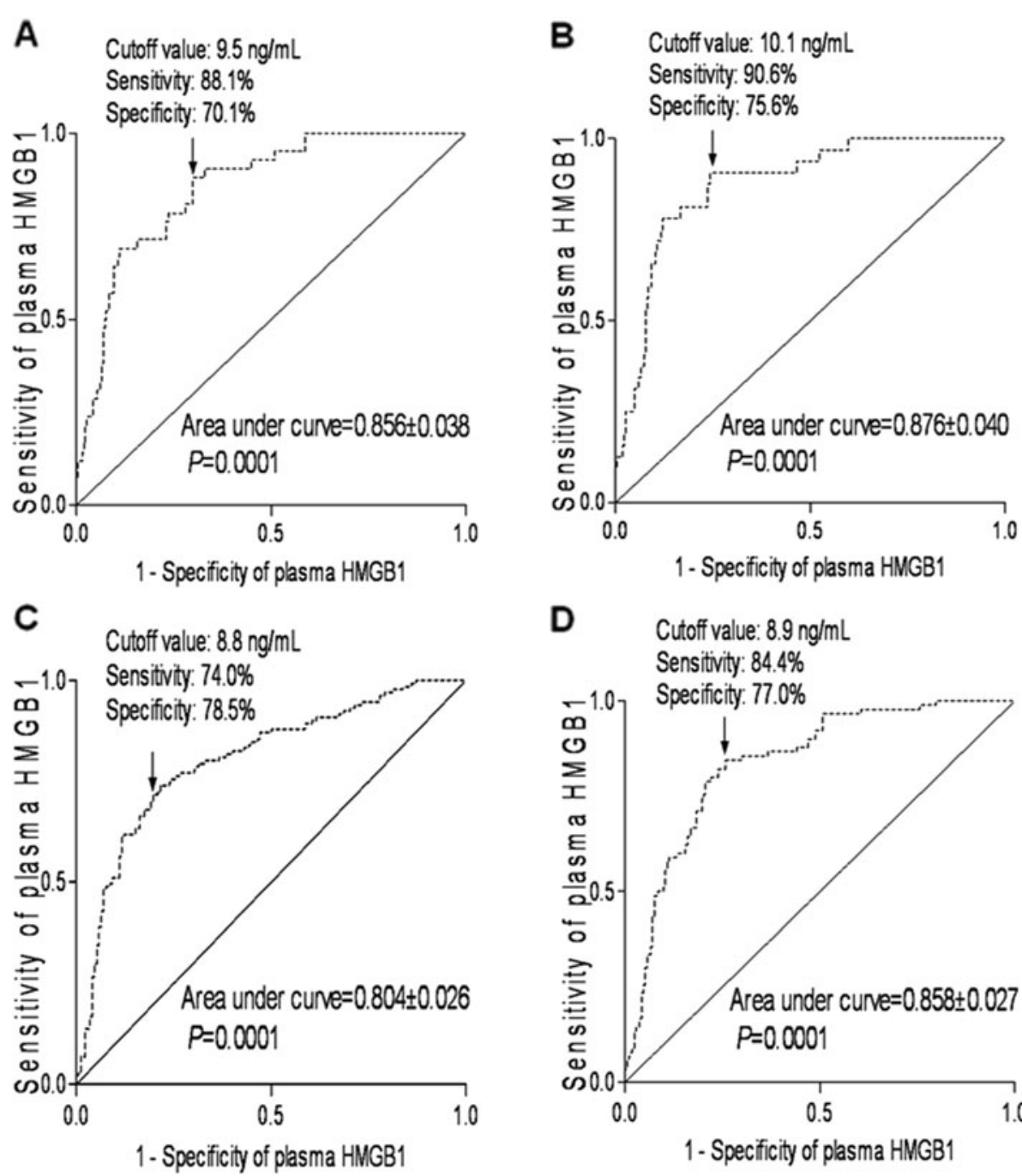

\section{Cutoff value: $8.9 \mathrm{ng} / \mathrm{mL}$ Sensitivity: $84.4 \%$}

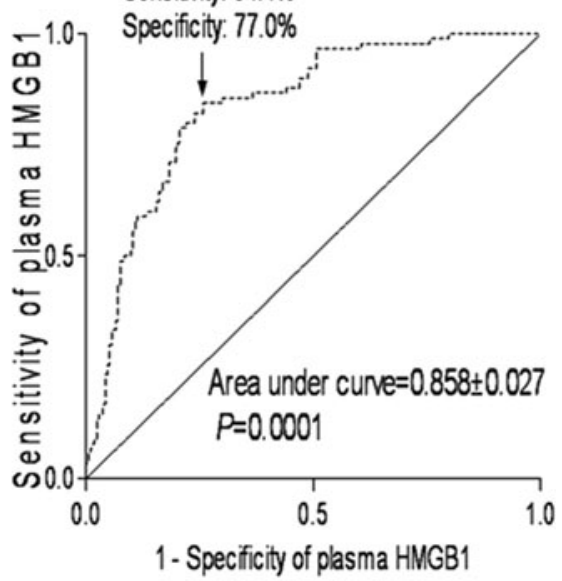

Figure 2 Graph showing receiver operating characteristic curve analysis of plasma high mobility group box-1 (HMGB1) level for (A) 1-year mortality, (B) in-hospital mortality, (C) cerebrovasospasm and (D) 1-year poor functional outcome.

Table 3 Receiver operating characteristic curve analysis of factors predicting the 1-year mortality among 303 patients

\begin{tabular}{|c|c|c|c|}
\hline & HMGB1 & WFNS score & Modified Fisher score \\
\hline Criterion & $>9.5 \mathrm{ng} / \mathrm{mL}$ & $>3$ & $>3$ \\
\hline Area under curve & 0.856 & 0.920 & 0.927 \\
\hline 95\% confidence interval & 0.812 to 0.894 & 0.884 to 0.948 & 0.892 to 0.954 \\
\hline Sensitivity & 88.1 & 78.6 & 88.1 \\
\hline 95\% confidence interval & 74.4 to 96.0 & 63.2 to 89.7 & 74.4 to 96.0 \\
\hline Specificity & 70.1 & 90.4 & 86.6 \\
\hline 95\% confidence interval & 64.2 to 75.6 & 86.2 to 93.7 & 81.8 to 90.5 \\
\hline + likelihood ratio & 2.95 & 8.20 & 6.57 \\
\hline 95\% confidence interval & 2.6 to 3.4 & 7.0 to 9.7 & 5.8 to 7.4 \\
\hline - likelihood ratio & 0.17 & 0.24 & 0.14 \\
\hline 95\% confidence interval & 0.07 to 0.4 & 0.1 to 0.5 & 0.06 to 0.3 \\
\hline$P$ value & Reference & 0.106 & 0.100 \\
\hline
\end{tabular}

HMGB1, high mobility group box-1; WFNS, World Federation of Neurological Surgeons. 
Table 4 The factors associated with in-hospital mortality

\begin{tabular}{|c|c|c|c|}
\hline & Non-survivors & Survivors & $P$ value \\
\hline & $(n=32)$ & $(n=271)$ & \\
\hline Sex (male/female) & $12 / 20$ & $119 / 152$ & 0.489 \\
\hline Age (years) & $45.4 \pm 12.9$ & $43.7 \pm 12.3$ & 0.469 \\
\hline WFNS score on admission & $3.9 \pm 0.7$ & $2.2 \pm 1.1$ & $<0.001$ \\
\hline $\begin{array}{l}\text { Modified Fisher score } \\
\text { on admission }\end{array}$ & $4.3 \pm 0.6$ & $2.6 \pm 0.8$ & $<0.001$ \\
\hline Aneurysmal location & & & 0.599 \\
\hline Posterior communication artery & $5(15.6 \%)$ & $78(28.8 \%)$ & \\
\hline Internal carotid artery & $6(18.8 \%)$ & $37(13.7 \%)$ & \\
\hline Anterior communication artery & $8(25.0 \%)$ & $58(21.4 \%)$ & \\
\hline Middle cerebral artery & $4(12.5 \%)$ & $41(15.1 \%)$ & \\
\hline Anterior cerebral artery & $4(12.5 \%)$ & $31(11.4 \%)$ & \\
\hline Posterior cerebral artery & $3(9.4 \%)$ & $20(7.4 \%)$ & \\
\hline Vertebral artery & $2(6.3 \%)$ & $6(2.2 \%)$ & \\
\hline Surgery & $17(53.1 \%)$ & $169(62.4 \%)$ & 0.310 \\
\hline Aneurysmal size (mm) & $11.9 \pm 5.1$ & $6.7 \pm 4.5$ & $<0.001$ \\
\hline Rebleeding & $6(18.8 \%)$ & $10(3.7 \%)$ & $<0.001$ \\
\hline Acute hydrocephalus & 19 (59.4\%) & $71(26.2 \%)$ & $<0.001$ \\
\hline Intracerebral hemorrhage & $15(46.9 \%)$ & $24(8.9 \%)$ & $<0.001$ \\
\hline Intraventricular hemorrhage & 31 (96.9\%) & $41(15.1 \%)$ & $<0.001$ \\
\hline External ventricular drain & $30(93.8 \%)$ & $79(29.2 \%)$ & $<0.001$ \\
\hline Angiographic vasospasm & $30(93.8 \%)$ & $101(37.3 \%)$ & $<0.001$ \\
\hline Computed tomography ischemia & $16(50.0 \%)$ & $34(12.6 \%)$ & $<0.001$ \\
\hline Admission time (hours) & $5.4 \pm 4.2$ & $4.6 \pm 3.6$ & 0.276 \\
\hline Seizure & $7(21.9 \%)$ & $37(13.7 \%)$ & 0.212 \\
\hline $\begin{array}{l}\text { Plasma C-reactive protein } \\
\text { level (mg/L) }\end{array}$ & $9.0 \pm 3.2$ & $6.9 \pm 2.6$ & $<0.001$ \\
\hline plasma D-dimer level (mg/L) & $2.4 \pm 1.1$ & $2.0 \pm 1.0$ & 0.045 \\
\hline Plasma HMGB1 level (ng/mL) & $13.1 \pm 3.1$ & $8.0 \pm 3.2$ & $<0.001$ \\
\hline
\end{tabular}

Numerical variables are presented as mean \pm standard deviation. Categorical variables are expressed as counts (percentage). Numerical variables were analyzed by Mann-Whitney U-test or unpaired Student $t$ test. Categorical variables were analyzed by chi-square test or Fisher exact test. HMGB1, high mobility group box-1; n, number of patients; WFNS, World Federation of Neurological Surgeons.

Written informed consent to participate in the study was obtained from the subjects or their relatives. This protocol was approved by the Ethics Committee of The Second Affiliated Hospital, School of Medicine, Zhejiang University before implementation.

\section{Clinical and radiological assessment}

On arrival at the emergency department, a detailed history of vascular risk factors, concomitant medication, Glasgow Coma Scale (GCS) score, body temperature, heart rate, respiratory rate and blood pressure were taken. At admission, clinical severity was assessed using WFNS score [2]. The initial CT was classified according to the modified Fisher score [3]. All CT scans were performed according to the neuroradiology department protocol. Investigators who read them were blinded to clinical information.

\section{Patient management}

The type of treatment (surgery or coiling) was decided according to both location and size of the aneurysm by the neurosurgeon and the neuroradiologist. All patients received intravenous nimodipine at a dose of $2 \mathrm{mg} /$ hour from admission until at least day 14 , except during periods of uncontrolled increased intracranial pressure during which intravenous nimodipine was discontinued. Seizures were systematically prevented by sodium valproate (200 $\mathrm{mg} \times 3$, per os). After surgery or coiling, those patients who had delayed ischemic neurological deficit or cerebrovasospasm were managed with 'triple $\mathrm{H}^{\prime}$ therapy (hypertension with a mean arterial pressure goal greater than $100 \mathrm{mmHg}$, hypervolemia and hemodilution with a goal hematocrit of 30) through 12 days after hemorrhage. An external ventricular drain was inserted in the case of hydrocephalus on CT and in patients with a high WFNS grade (WFNS score of 3 to 5). Increased intracranial pressure was treated by cerebrospinal fluid drainage, mechanical ventilation, reinforcement of sedation, and, rarely, moderate hypothermia. CT was performed whenever clinical deterioration occurred to search for secondary complications such as hydrocephalus or ischemia.

Clinical onset of cerebral vasospasm was defined as the acute onset of a focal neurologic deficit or a change in the GCS score of 2 or more points. All suspected cases of cerebral vasospasms were confirmed by CT angiography and were then taken to the interventional radiology suite for cerebral angiography. Each vasospasm episode was treated with intra-arterial administration of nimodipine as recently described. This therapy was repeated if necessary. Balloon angioplasty was used as a second-line therapy when nimodipine was judged insufficient. Computed tomography ischemia was referred to as delayed ischemia attributed to vasospasm.

\section{Determination of HMGB1 in plasma}

Informed consents were obtained from the study population or family members in all cases before blood was collected. In the control group, venous blood was drawn at study entry. In the SAH patients, venous blood was drawn on admission. The blood samples were immediately placed into sterile EDTA test tubes and centrifuged at $1500 \mathrm{~g}$ for 20 minutes at $4^{\circ} \mathrm{C}$ to collect plasma. Plasma was stored at $-70^{\circ} \mathrm{C}$ until assayed. The concentration of HMGB1 in plasma was analyzed by ELISA using commercial kits (SHINO-TEST Corporations, Kanagawa, Japan) in accordance with the manufacturers' 
Table 5 Receiver operating characteristic curve analysis of factors predicting the in-hospital mortality among 303 patients

\begin{tabular}{|c|c|c|c|}
\hline & HMGB1 & WFNS score & Modified Fisher score \\
\hline Criterion & $>10.1 \mathrm{ng} / \mathrm{mL}$ & $>3$ & $>3$ \\
\hline Area under curve & 0.876 & 0.893 & 0.922 \\
\hline 95\% confidence interval & 0.833 to 0.911 & 0.853 to 0.926 & 0.886 to 0.950 \\
\hline Sensitivity & 90.6 & 75.0 & 90.6 \\
\hline 95\% confidence interval & 75.0 to 97.9 & 56.6 to 88.5 & 75.0 to 97.9 \\
\hline Specificity & 75.6 & 87.5 & 84.1 \\
\hline 95\% confidence interval & 70.1 to 80.6 & 82.9 to 91.2 & 79.2 to 88.3 \\
\hline + likelihood ratio & 3.72 & 5.98 & 5.71 \\
\hline 95\% confidence interval & 3.3 to 4.2 & 4.9 to 7.3 & 5.1 to 6.5 \\
\hline - likelihood ratio & 0.12 & 0.29 & 0.11 \\
\hline 95\% confidence interval & 0.04 to 0.4 & 0.1 to 0.6 & 0.04 to 0.3 \\
\hline$P$ value & Reference & 0.707 & 0.328 \\
\hline
\end{tabular}

HMGB1, high mobility group box-1; WFNS, World Federation of Neurological Surgeons.

instructions. The blood samples were run in duplicate. Researchers running ELISAs were blinded to all patient details.

\section{End point}

Participants were followed up until death or completion of 1 year after SAH. Their primary outcome was death (at 1 year or in-hospital) and their secondary outcomes were vasospasm and functional outcome at 1 year. The functional outcome was defined by Glasgow outcome scale (GOS) score. GOS was defined as follows: $1=$ death; $2=$ persistent vegetative state; $3=$ severe disability; $4=$ moderate disability; and $5=$ good recovery [26]. GOS Scores were dichotomized in good and poor functional outcomes (GOS of 4 to 5 vs. GOS of 1 to 3 ). For follow-up, we used structure telephone interviews performed by one doctor, blinded to clinical information, and copeptin levels.

\section{Statistical analysis}

Statistical analysis was performed with SPSS 10.0 (SPSS Inc., Chicago, IL, USA) and MedCalc 9.6.4.0. (MedCalc Software, Mariakerke, Belgium). The normality of data distribution was assessed by the Kolmogorovor-Smirnov test or Shapiro-Wilk test. All values are expressed as mean \pm standard deviation or counts (percentage) unless otherwise specified. Comparisons were made by using (1) chi-square test or Fisher exact test for categorical data, (2) unpaired Student $t$ test for continuous normally distributed variables, and (3) the Mann-Whitney U-test for continuous non-normally distributed variables. The correlations of HMGB1 with WFNS grade and Fisher grade were assessed by Spearman's correlation coefficient. The relations of HMGB1 to the poor functional outcome (GOS 1 to 3), death and cerebrovasospasm were assessed in a binary logistic-regression model. For multivariate analysis, we included the significantly different outcome predictors as assessed in univariate analysis. A receiver operating characteristic curve was configured to establish the cutoff point of plasma HMGB1 with the optimal sensitivity and specificity for predicting the poor functional outcome (GOS 1 to 3), death and cerebrovasospasm. In a combined logistic-regression model, we estimated the additive benefit of HMGB1 to other predictors (WFNS grade and Fisher grade). A $P$ value of less than 0.05 was considered statistically significant.

\section{Results}

\section{Study population characteristics}

During the recruitment period 347 patients were admitted with an initial diagnosis of aneurysmal SAH, 312 (89.9\%) patients fulfilled the inclusion criteria, and adequate data on admission and follow-up were available for 303 individuals (87.3\%) who were finally included in the analysis (Figure 1). Table 1 summarizes the demographic, clinical, laboratory and radiological data of the patients. One hundred and fifty healthy subjects were eligible as controls. The intergroup differences in the age and sex were not statistically significant. After SAH, plasma HMGB1 level on admission in patients was statistically significantly higher than that in healthy controls $(8.5 \pm 3.6 \mathrm{ng} / \mathrm{mL}$ vs. $1.3 \pm 0.4 \mathrm{ng} / \mathrm{mL} ; P<0.001)$. Moreover, a significant correlation emerged between plasma HMGB1 level and WFNS score $(\mathrm{r}=0.635, P<0.001)$, as well as between plasma HMGB1 level and modified Fisher score $(\mathrm{r}=0.624, P<0.001)$.

\section{One-year mortality prediction}

Forty-two patients (13.9\%) died from SAH in 1 year. Higher plasma HMGB1 level was associated with 1-year 
Table 6 The factors associated with cerebrovasospasm

\begin{tabular}{|c|c|c|c|}
\hline & $\frac{\text { Vasospasm }}{(n=131)}$ & $\frac{\text { Non-vasospasm }}{(n=172)}$ & $P$ value \\
\hline Sex (male/female) & $61 / 70$ & $70 / 102$ & 0.307 \\
\hline Age (years) & $43.8 \pm 12.2$ & $43.9 \pm 12.5$ & 0.973 \\
\hline WFNS score on admission & $3.2 \pm 1.1$ & $1.7 \pm 0.9$ & $<0.001$ \\
\hline Modified Fisher score on admission & $3.5 \pm 1.0$ & $2.2 \pm 0.6$ & $<0.001$ \\
\hline Aneurysmal location & & & 0.813 \\
\hline Posterior communication artery & $33(25.2 \%)$ & $50(29.1 \%)$ & \\
\hline Internal carotid artery & $20(15.3 \%)$ & $23(13.4 \%)$ & \\
\hline Anterior communication artery & $29(22.1 \%)$ & $37(21.5 \%)$ & \\
\hline Middle cerebral artery & $22(16.8 \%)$ & $23(13.4 \%)$ & \\
\hline Anterior cerebral artery & $16(12.2 \%)$ & $19(11.0 \%)$ & \\
\hline Posterior cerebral artery & $7(5.3 \%)$ & $16(9.3 \%)$ & \\
\hline Vertebral artery & $4(3.1 \%)$ & $4(2.3 \%)$ & \\
\hline Surgery & $86(65.5 \%)$ & $100(58.1 \%)$ & 0.183 \\
\hline Aneurysmal size $(\mathrm{mm})$ & $9.1 \pm 5.7$ & $5.8 \pm 3.5$ & $<0.001$ \\
\hline Rebleeding & $10(7.6 \%)$ & $6(3.5 \%)$ & 0.110 \\
\hline Acute hydrocephalus & $71(54.2 \%)$ & $19(11.0 \%)$ & $<0.001$ \\
\hline Intracerebral hemorrhage & $26(19.9 \%)$ & $13(7.6 \%)$ & 0.002 \\
\hline Intraventricular hemorrhage & $52(39.7 \%)$ & $20(11.6 \%)$ & $<0.001$ \\
\hline External ventricular drain & $90(68.7 \%)$ & $19(11.0 \%)$ & $<0.001$ \\
\hline Admission time (hours) & $4.5 \pm 3.4$ & $4.9 \pm 3.8$ & 0.342 \\
\hline Seizure & $17(13.0 \%)$ & $27(15.7 \%)$ & 0.505 \\
\hline Systolic arterial pressure $(\mathrm{mmHg})$ & $134.2 \pm 23.6$ & $128.7 \pm 21.2$ & 0.033 \\
\hline Diastolic arterial pressure $(\mathrm{mmHg})$ & $81.1 \pm 15.1$ & $77.5 \pm 13.8$ & 0.031 \\
\hline Mean arterial pressure $(\mathrm{mmHg})$ & $98.8 \pm 16.1$ & $94.6 \pm 15.3$ & 0.020 \\
\hline Plasma C-reactive protein level (mg/L) & $7.9 \pm 3.0$ & $6.6 \pm 2.4$ & $<0.001$ \\
\hline plasma D-dimer level (mg/L) & $2.2 \pm 1.1$ & $1.9 \pm 0.9$ & 0.011 \\
\hline Plasma HMGB1 level (ng/mL) & $10.6 \pm 3.4$ & $7.0 \pm 2.9$ & $<0.001$ \\
\hline
\end{tabular}

Numerical variables are presented as mean \pm standard deviation. Categorical variables are expressed as counts (percentage). Numerical variables were analyzed by Mann-Whitney U-test or unpaired Student $t$ test. Categorical variables were analyzed by chi-square test or Fisher exact test. HMGB1, high mobility group box-1; $\mathrm{n}$, number of patients; WFNS, World Federation of Neurological Surgeons.

mortality, as well as other variables shown in Table 2 . When the above variables that were found to be significant in the univariate analysis were introduced into the logistic model, a multivariate analysis selected WFNS score (odds ratio, 7.491; 95\% confidence interval (CI) 1.361 to $21.351 ; P=0.001$ ), modified Fisher score (odds ratio, $9.292 ; 95 \% \mathrm{CI} 2.346$ to $23.318 ; P=0.005$ ) and plasma HMGB1 level (odds ratio, 2.117; 95\% CI 1.109 to $7.230 ; P=0.002$ ) as the independent predictors for 1 -year mortality of patients.

A receiver operating characteristic curve showed that plasma HMGB1 level on admission statistically significantly predicted 1-year mortality of patients (Figure 2A). The predictive value of the HMGB1 concentration was similar to those of WFNS score and modified Fisher score (Table 3). In a combined logistic-regression model,
HMGB1 did not statistically significantly improve the area under the curve of WFNS score $(P=0.107)$ or modified Fisher score $(P=0.160)$.

\section{In-hospital mortality prediction}

Thirty-two patients $(10.6 \%)$ died from SAH in the hospital. Higher plasma HMGB1 level was associated with in-hospital mortality, as well as other variables shown in Table 4. When the above variables that were found to be significant in the univariate analysis were introduced into the logistic model, a multivariate analysis selected WFNS score (odds ratio, 4.877; 95\% CI 1.448 to 14.301 ; $P=0.002$ ), modified Fisher score (odds ratio, 5.624; $95 \%$ CI 2.119 to $16.993 ; P=0.008$ ) and plasma HMGB1 level (odds ratio, 2.245 ; $95 \%$ CI 1.218 to $8.949 ; P=0.005$ ) as 
Table 7 Receiver operating characteristic curve analysis of factors predicting the cerebrovasospasm among 303 patients

\begin{tabular}{|c|c|c|c|}
\hline & HMGB1 & WFNS score & Modified Fisher score \\
\hline Criterion & $>8.8 \mathrm{ng} / \mathrm{mL}$ & $>2$ & $>2$ \\
\hline Area under curve & 0.804 & 0.879 & 0.874 \\
\hline 95\% confidence interval & 0.754 to 0.847 & 0.837 to 0.913 & 0.831 to 0.909 \\
\hline Sensitivity & 74.0 & 80.9 & 84.7 \\
\hline 95\% confidence interval & 65.7 to 81.3 & 73.1 to 87.3 & 77.4 to 90.4 \\
\hline Specificity & 78.5 & 79.7 & 76.7 \\
\hline 95\% confidence interval & 71.6 to 84.4 & 72.9 to 85.4 & 69.4 to 82.2 \\
\hline + likelihood ratio & 3.44 & 3.98 & 3.64 \\
\hline 95\% confidence interval & 3.0 to 3.9 & 3.6 to 4.4 & 3.3 to 4.1 \\
\hline - likelihood ratio & 0.33 & 0.24 & 0.20 \\
\hline 95\% confidence interval & 0.2 to 0.5 & 0.2 to 0.4 & 0.1 to 0.3 \\
\hline$P$ value & Reference & 0.016 & 0.017 \\
\hline
\end{tabular}

HMGB1, high mobility group box-1; WFNS, World Federation of Neurological Surgeons.

the independent predictors for in-hospital mortality of patients.

A receiver operating characteristic curve showed that plasma HMGB1 level on admission statistically significantly predicted in-hospital mortality of patients (Figure 2B). The predictive value of the HMGB1 concentration was similar to those of WFNS score and modified Fisher score (Table 5). In a combined logistic-regression model, HMGB1 did not statistically significantly improve the area under the curve of WFNS score $(P=0.140)$ or modified Fisher score $(P=0.161)$.

\section{Cerebrovasospasm prediction}

One hundred and thirty-one (43.2\%) suffered from cerebrovasospasm in the hospital. Higher plasma HMGB1 level was associated with cerebrovasospasm, as well as other variables shown in Table 6 . When the above variables that were found to be significant in the univariate analysis were introduced into the logistic model, a multivariate analysis selected WFNS score (odds ratio, 3.890; 95\% CI 1.230 to $8.421 ; P=0.008)$, modified Fisher score (odds ratio, $4.713 ; 95 \%$ CI 1.689 to $15.106 ; P=0.001$ ) and plasma HMGB1 level (odds ratio, 1.249; 95\% CI 1.132 to $1.871 ; P=0.011$ ) as the independent predictors for cerebrovasospasm of patients.

A receiver operating characteristic curve showed that plasma HMGB1 level on admission statistically significantly predicted cerebrovasospasm of patients (Figure 2C). The predictive value of the HMGB1 concentration was lower than those of WFNS score and modified Fisher score (Table 7). In a combined logistic-regression model, HMGB1 did not statistically significantly improve the area under the curve of WFNS score $(P=0.218)$ or modified Fisher score $(P=0.235)$.

\section{Poor neurologic function prediction}

Ninety patients (29.7\%) suffered from poor neurologic outcome (GOS 1-3) in 1 year. Higher plasma HMGB1 level was associated with 1-year poor neurologic outcome, as well as other variables shown in Table 8 . When the above variables that were found to be significant in the univariate analysis were introduced into the logistic model, a multivariate analysis selected WFNS score (odds ratio, 4.872; 95\% CI 1.945 to $13.760 ; P=0.004$ ), modified Fisher score (odds ratio, 5.981; 95\% CI 2.519 to 15.379; $P=0.003$ ) and plasma HMGB1 level (odds ratio, $1.410 ; 95 \%$ CI 1.112 to $1.914 ; P=0.002$ ) as the independent predictors for 1-year poor neurologic outcome of patients.

A receiver operating characteristic curve showed that plasma HMGB1 level on admission predicted 1-year poor neurologic outcome of patients statistically significantly (Figure 2D). The predictive value of the HMGB1 concentration was similar to those of WFNS score and modified Fisher score (Table 9). In a combined logisticregression model, HMGB1 statistically significantly improved the area under curve of WFNS score $(P=0.007)$ and modified Fisher score $(P=0.014)$.

\section{Discussion}

This study was conducted to determine if plasma HMGB1 is increased in the circulation of humans with $\mathrm{SAH}$ and whether this enhancement correlates with in-hospital mortality, cerebrovasospasm and 1-year poor clinical outcomes in these patients. The admission plasma HMGB1 levels were indeed significantly increased in all patients compared with healthy subjects. Furthermore, an admission plasma HMGB1 level was identified as a reliable and independent marker to predict patients at risk of inhospital mortality, cerebrovasospasm and 1-year poor 
Table 8 The factors associated with 1-year function outcome

\begin{tabular}{|c|c|c|c|}
\hline & $\frac{\text { GOS } 1 \text { to } 3}{(n=90)}$ & $\frac{\text { GOS } 4 \text { to } 5}{(n=213)}$ & $P$ value \\
\hline Sex (male/female) & $42 / 48$ & $89 / 124$ & 0.433 \\
\hline Age (years) & $44.7 \pm 11.3$ & $43.5 \pm 12.8$ & 0.422 \\
\hline WFNS score on admission & $3.6 \pm 0.7$ & $1.8 \pm 0.9$ & $<0.001$ \\
\hline $\begin{array}{l}\text { Modified Fisher score } \\
\text { on admission }\end{array}$ & $3.8 \pm 0.8$ & $2.3 \pm 0.7$ & $<0.001$ \\
\hline Aneurysmal location & & & 0.291 \\
\hline Posterior communication artery & $24(26.7 \%)$ & $59(27.7 \%)$ & \\
\hline Internal carotid artery & $13(14.4 \%)$ & $30(14.1 \%)$ & \\
\hline Anterior communication artery & $17(18.9 \%)$ & $49(23.0 \%)$ & \\
\hline Middle cerebral artery & $14(15.6 \%)$ & $31(14.6 \%)$ & \\
\hline Anterior cerebral artery & $7(7.8 \%)$ & $28(13.1 \%)$ & \\
\hline Posterior cerebral artery & $11(12.2 \%)$ & $12(5.6 \%)$ & \\
\hline Vertebral artery & $4(4.4 \%)$ & $4(1.9 \%)$ & \\
\hline Surgery & $54(60.0 \%)$ & $132(62.0 \%)$ & 0.747 \\
\hline Aneurysmal size (mm) & $10.4 \pm 5.8$ & $5.9 \pm 3.7$ & $<0.001$ \\
\hline Rebleeding & $10(11.1 \%)$ & $6(2.8 \%)$ & 0.003 \\
\hline Acute hydrocephalus & $47(52.2 \%)$ & $43(20.2 \%)$ & $<0.001$ \\
\hline Intracerebral hemorrhage & $20(22.2 \%)$ & $19(8.9 \%)$ & 0.002 \\
\hline Intraventricular hemorrhage & $59(65.6 \%)$ & $12(5.6 \%)$ & $<0.001$ \\
\hline External ventricular drain & $66(73.3 \%)$ & $43(20.2 \%)$ & $<0.001$ \\
\hline Angiographic vasospasm & $71(78.9 \%)$ & $60(28.2 \%)$ & $<0.001$ \\
\hline Computed tomography ischemia & $28(31.1 \%)$ & $22(10.3 \%)$ & $<0.001$ \\
\hline Admission time (hours) & $4.5 \pm 3.5$ & $4.8 \pm 3.7$ & 0.577 \\
\hline Seizure & $19(21.1 \%)$ & $25(11.7 \%)$ & 0.085 \\
\hline $\begin{array}{l}\text { Plasma C-reactive protein } \\
\text { level (mg/L) }\end{array}$ & $8.2 \pm 3.2$ & $6.7 \pm 2.4$ & $<0.001$ \\
\hline plasma D-dimer level (mg/L) & $2.4 \pm 1.2$ & $1.9 \pm 0.9$ & $<0.001$ \\
\hline Plasma HMGB1 level (ng/mL) & $11.5 \pm 3.1$ & $7.3 \pm 3.0$ & $<0.001$ \\
\hline
\end{tabular}

Numerical variables are presented as mean \pm standard deviation. Categorical variables are expressed as counts (percentage). Numerical variables were analyzed by Mann-Whitney U-test or unpaired Student $t$ test. Categorical variables were analyzed by chi-square test or Fisher exact test. GOS, Glasgow Outcome Scale; HMGB1, high mobility group box-1; n, number of patients; WFNS, World Federation of Neurological Surgeons.

clinical outcome. Importantly, the prognostic values of HMGB1 were similar to those of WFNS score and modified Fisher score for in-hospital mortality and 1-year poor clinical outcome, substantiating its potential as a new prognostic biomarker.

HMGB1 is a non-histone DNA binding protein that possesses two HMG boxes that are DNA binding domains [27]. As a chromosomal protein, HMGB1 has been implicated in diverse intracellular functions, including the stabilization of nucleosomal structure and the facilitation of gene transcription [28]. Moreover, some evidence identifies HMGB1 as a cytokine-like mediator of delayed endotoxin lethality and acute lung injury $[7,29]$. HMGB1 is actively secreted by macrophages and monocytes or released by necrotic cells into the extracellular milieu, where it might be involved in the triggering of inflammation $[7,8,29,30]$. Recombinant HMGB1 has been found to induce acute inflammation in animal models of lung injury and endotoxemia [7,29], and anti-HMGB1 antibody attenuated endotoxin-induced lethality even when administration of antibody was delayed until after early cytokine response [7,31]. In addition, high serum levels of HMGB1 in patients with sepsis or hemorrhagic shock have been reported to be associated with increased mortality and disease severity $[7,32]$.

HMGB1 is widely expressed in various tissues including the brain [13-15]. Moreover, in the brain, HMGB1 has been reported to be released after cytokine stimulation and to be involved in the inflammatory process after it was administered intracerebroventricularly [16,33]. A recent study demonstrates that HMGB1 is massively released into the extracellular milieu during the acute damaging phase and that extracellular HMGB1 might function as a proinflammatory cytokine, activate microglia, and hence stimulate the release of other cytokines and aggravate brain injury in the postischemic brain [17]. Furthermore, $\mathrm{HMGB1}^{-1-}$ necrotic cells have a greatly reduced ability to promote inflammation [8]. Although the mechanism by which HMGB1 exerts its proinflammatory cytokine-like effects in the central nervous system is unknown, previous reports have shown that the activations of several mitogen activated protein kinases and nuclear factor kappa B are involved in the proinflammatory effect of HMGB1 [34-36]. These are downstream molecules of receptors for advanced glycation end product or Toll-like receptor family members, which are important receptors in the HMGB1 signaling process [37-40]. Evidence is rapidly accumulating to suggest that HMGB1 may play an important role in brain injury following stroke. Muhammad and colleagues [41] have demonstrated using a mouse middle cerebral artery occlusion model that HMGB1 engagement of receptors for advanced glycation end product triggers inflammation and infarction leading to ischemic brain injury. Recent studies have also reported elevated HMGB1 levels in the cerebrospinal fluid of SAH patients with poor outcome $[24,25]$. Moreover, another report also found elevated cytosolic HMGB1 in brain parenchyma of SAH animals [15]. To our knowledge, our present study represents the first report of elevated HMGB1 levels in plasma of SAH patients. In our study, a high WFNS score or modified Fisher score upon admission was strongly correlated with the high plasma HMGB1 level. Our data suggest that plasma HMGB1 level in this early period might reflect the initial hemorrhage insult. Connected with the previous studies, our results suggest 
Table 9 Receiver operating characteristic curve analysis of factors predicting 1-year poor functional outcome among 303 patients

\begin{tabular}{|c|c|c|c|}
\hline & HMGB1 & WFNS score & Modified Fisher score \\
\hline Criterion & $>8.9 \mathrm{ng} / \mathrm{mL}$ & $>2$ & $>2$ \\
\hline Area under curve & 0.858 & 0.909 & 0.902 \\
\hline 95\% confidence interval & 0.813 to 0.895 & 0.871 to 0.939 & 0.863 to 0.933 \\
\hline Sensitivity & 84.4 & 96.7 & 95.6 \\
\hline 95\% confidence interval & 75.3 to 91.2 & 90.6 to 99.3 & 89.0 to 98.7 \\
\hline Specificity & 77.0 & 74.7 & 69.5 \\
\hline 95\% confidence interval & 70.8 to 82.5 & 68.3 to 80.3 & 62.8 to 75.6 \\
\hline + likelihood ratio & 3.67 & 3.81 & 3.13 \\
\hline 95\% confidence interval & 3.3 to 4.1 & 3.5 to 4.2 & 2.8 to 3.5 \\
\hline - likelihood ratio & 0.2 & 0.045 & 0.064 \\
\hline 95\% confidence interval & 0.1 to 0.3 & 0.01 to 0.1 & 0.02 to 0.2 \\
\hline$P$ value & Reference & 0.104 & 0.163 \\
\hline
\end{tabular}

HMGB1, high mobility group box-1; WFNS, World Federation of Neurological Surgeons.

HMGB1 may act in concert to promote brain inflammation following SAH.

In this study, a receiver operating characteristic curve showed that plasma HMGB1 level on admission predicted poor functional outcome and mortality after 1 year, and in-hospital mortality of patients obviously. The area under the curve of the HMGB1 concentration was similar to those of WFNS score and modified Fisher score for the prediction of these poor outcomes. In a combined logistic-regression model, HMGB1 improved the area under the curve of WFNS score and modified Fisher score for the prediction of poor functional outcome after 1 year, but not for the prediction of mortality after 1 year or in-hospital mortality. Therefore, the determination of HMGB1 in the plasma of patients on admission provides the ability to distinguish between patients with good and bad outcome. Cerebrovasospasm is regarded as abnormal and prolonged smooth muscle contraction of cerebral arteries; many substances have been involved in the development of cerebral vasospasm following $\mathrm{SAH}$, but the complex mechanism of this arterial narrowing is not yet fully understood [42,43]. The degree of angiographic vasospasm is not always well correlated with the development of neurological deficits in SAH patients, and other influences such as early brain injury due to cortical spreading depression, disruption of the blood-brain barrier, impaired function of the microcirculation, inflammation, and apoptotic cell death may contribute to SAH-induced pathologies [44-48]. This study found that plasma HMGB1 level was an independent predictor for cerebrovasospasm of patients. However, significantly lower accuracy for the prediction of cerebrovasospasm was found for plasma HMGB1 level compared with other clinical grade such as WFNS and modified Fisher score. Hence, plasma levels of HMGB1 on admission are not recommended for the prediction of cerebrovasospasm after SAH. Overall, plasma HMGB1 level has low accuracy for the prediction of cerebrovasospasm and high accuracy for the prediction of 1-year mortality or in-hospital mortality or 1-year poor functional outcome. However, HMGB1 determination does not add to the accuracy of prediction of the clinical outcomes.

In addition, location of the subarachnoid blood can be assessed in the following four anatomical locations: convexity, sylvian fissure, basal cistern, and interhemisphere. However, most of the subarachnoid blood resides in multiple anatomical locations leading to difficulty of classification. Hence, whether HMGB1 levels differ according to SAH location warrants further investigation; maybe this is a limitation in this study. Actually, subarachnoid blood is impossible to gather in just an anatomical location. We need to mention that, in this study, ischemic or hemorrhage stroke referred to stroke in the patients' history. Patients with previous neurological diseases including ischemic or hemorrhagic stroke, or the use of antiplatelet or anticoagulant medication, were excluded because these patients were complicated with vascular risk factors including diabetes mellitus and/or hypertension that were associated with high HMGB1 level [49-52] and became the confounding variables.

\section{Conclusions}

In this study, plasma HMGB1 level is a useful, complementary tool to predict functional outcome and mortality after aneurysmal SAH. However, HMGB1 determination does not add to the accuracy of prediction of the clinical outcome. 


\section{Abbreviations}

Cl: confidence interval; CT: computerized tomography; ELISA: enzyme-linked immunosorbent assay; GCS: Glasgow Coma Scale; GOS: Glasgow outcome scale; HMGB1: high mobility group box-1; SAH: subarachnoid hemorrhage; WFNS: World Federation of Neurological Surgeons.

\section{Competing interests}

The authors declare that they have no competing interests.

\section{Authors' contributions}

XDZ and JSC contributed to the design of the study and drafted the manuscript and participated in the laboratory work. JSC, FZ and QCL enrolled the patients. GC and JMZ contributed to data analysis and interpretation of the results. All authors read and approved the final manuscript.

Received: 6 April 2012 Accepted: 24 July 2012

Published: 11 August 2012

\section{References}

1. Liebenberg WA, Worth R, Firth GB, Olney J, Norris JS: Aneurysmal subarachnoid haemorrhage: guidance in making the correct diagnosis. Postgrad Med J 2005, 81:470-473.

2. Drake C: Report of world federation of neurological surgeons committee on a universal subarachnoid hemorrhage grading scale. J Neurosurg 1988, 68:985-986

3. Fisher CM, Kistler JP, Davis JM: Relation of cerebral vasospasm to subarachnoid hemorrhage visualized by computerized tomographic scanning. Neurosurgery 1980, 6:1-9.

4. Turck N, Vutskits L, Sanchez-Pena P, Robin X, Hainard A, Gex-Fabry M, Fouda C, Bassem H, Mueller M, Lisacek F, Puybasset L, Sanchez JC: A multiparameter panel method for outcome prediction following aneurysmal subarachnoid hemorrhage. Intensive Care Med 2010 36:107-115.

5. Goodwin GH, Sanders C, Johns EW: A new group of chromatin-associated proteins with a high content of acidic and basic amino acids. Eur J Biochem 1973, 38:14-19.

6. Javaherian K, Liu JF, Wang JC: Nonhistone proteins HMG1 and HMG2 change the DNA helical structure. Science 1978, 199:1345-1346.

7. Wang $\mathrm{H}$, Bloom $\mathrm{O}$, Zhang M, Vishnubhakat JM, Ombrellino M, Che J, Frazier A, Yang H, Ivanova S, Borovikova L, Manogue KR, Faist E, Abraham E, Andersson J, Andersson U, Molina PE, Abumrad NN, Sama A, Tracey KJ: HMG-1 as a late mediator of endotoxin lethality in mice. Science 1999, 285:248-251.

8. Scaffidi P, Misteli T, Bianchi ME: Release of chromatin protein HMGB1 by necrotic cells triggers inflammation. Nature 2002, 418:191-195.

9. Lotze MT, Tracey KJ: High-mobility group box 1 protein (HMGB1): nuclear weapon in the immune arsenal. Nat Rev Immunol 2005, 5:331-342.

10. Dumitriu IE, Baruah P, Manfredi AA, Bianchi ME, Rovere-Querini P: HMGB1: guiding immunity from within. Trends Immunol 2005, 26:381-387.

11. Bianchi ME, Manfredi AA: High-mobility group box 1 (HMGB1) protein at the crossroads between innate and adaptive immunity. Immunol Rev 2007, 220:35-46.

12. Klune JR, Dhupar R, Cardinal J, Billiar TR, Tsung A: HMGB1: endogenous danger signaling. Mol Med 2008, 14:476-484.

13. Guazzi S, Strangio A, Franzi AT, Bianchi ME: HMGB1, an architectural chromatin protein and an extracellular signaling factor, has a spatially and temporally restricted expression pattern in mouse brain. Gene Expr Patterns 2003, 3:29-33.

14. Watanabe M, Miyajima M, Nakajima M, Arai H, Ogino I, Nakamura S, Kunichika M: Expression analysis of high mobility group box-1 protein (HMGB-1) in the cerebral cortex, hippocampus, and cerebellum of the congenital hydrocephalus (H-Tx) rat. Acta Neurochir Suppl 2012, 113:91-96.

15. Murakami K, Koide M, Dumont TM, Russell SR, Tranmer BI, Wellman GC: Subarachnoid hemorrhage induces gliosis and increased expression of the pro-inflammatory cytokine high mobility group box 1 protein. Trans/ Stroke Res 2011, 2:72-79.

16. Agnello D, Wang $H$, Yang H, Tracey KJ, Ghezzi P: HMGB-1, a DNA-binding protein with cytokine activity, induces brain TNF and IL-6 production, and mediates anorexia and taste aversion. Cytokine 2002, 18:231-236.
17. Kim JB, Sig Choi J, Yu YM, Nam K, Piao CS, Kim SW, Lee MH, Han PL, Park JS, Lee JK: HMGB1, a novel cytokine-like mediator linking acute neuronal death and delayed neuroinflammation in the postischemic brain. J Neurosci 2006, 26:6413-6421.

18. O'Connor KA, Hansen MK, Rachal Pugh C, Deak MM, Biedenkapp JC, Milligan ED, Johnson JD, Wang H, Maier SF, Tracey KJ, Watkins LR: Further characterization of high mobility group box 1 (HMGB1) as a proinflammatory cytokine: central nervous system effects. Cytokine 2003, 24:254-265.

19. Takata K, Kitamura Y, Kakimura J, Shibagaki K, Tsuchiya D, Taniguchi T, Smith MA, Perry G, Shimohama S: Role of high mobility group protein-1 (HMG1) in amyloid-beta homeostasis. Biochem Biophys Res Commun 2003, 301:699-703.

20. Takata K, Kitamura Y, Tsuchiya D, Kawasaki T, Taniguchi T, Shimohama S: High mobility group box protein-1 inhibits microglial Abeta clearance and enhances Abeta neurotoxicity. J Neurosci Res 2004, 78:880-891.

21. Pedrazzi M, Patrone M, Passalacqua M, Ranzato E, Colamassaro D, Sparatore B, Pontremoli S, Melloni E: Selective proinflammatory activation of astrocytes by high-mobility group box 1 protein signaling. J Immunol 2007, 179:8525-8532.

22. Tang D, Kang R, Cao L, Zhang G, Yu Y, Xiao W, Wang H, Xiao X: A pilot study to detect high mobility group box 1 and heat shock protein 72 in cerebrospinal fluid of pediatric patients with meningitis. Crit Care Med 2008, 36:291-295.

23. Goldstein RS, Gallowitsch-Puerta M, Yang L, Rosas-Ballina M, Huston JM, Czura CJ, Lee DC, Ward MF, Bruchfeld AN, Wang H, Lesser ML, Church AL, Litroff AH, Sama AE, Tracey KJ: Elevated high-mobility group box 1 levels in patients with cerebral and myocardial ischemia. Shock 2006, 25:571-574

24. Nakahara T, Tsuruta R, Kaneko T, Yamashita S, Fujita M, Kasaoka S, Hashiguchi T, Suzuki M, Maruyama I, Maekawa T: High-mobility group box 1 protein in CSF of patients with subarachnoid hemorrhage. Neurocrit Care 2009, 11:362-368

25. King MD, Laird MD, Ramesh SS, Youssef P, Shakir B, Vender JR, Alleyne CH, Dhandapani KM: Elucidating novel mechanisms of brain injury following subarachnoid hemorrhage: an emerging role for neuroproteomics. Neurosurg Focus 2010, 28:E10.

26. Jennett $B$, Bond $M$ : Assessment of outcome after severe brain damage. Lancet 1975, 1:480-484.

27. Landsman D, Bustin MA: Signature for the HMG-1 box DNA-binding proteins. Bioessays 1993, 15:539-546.

28. Bustin M: Regulation of DNA-dependent activities by the functional motifs of the high-mobility-group chromosomal proteins. Mol Cell Biol 1999, 19:5237-5246.

29. Abraham E, Arcaroli J, Carmody A, Wang H, Tracey KJ: HMG-1 as a mediator of acute lung inflammation. J Immunol 2000, 165:2950-2954.

30. Bonaldi T, Talamo F, Scaffidi P, Ferrera D, Porto A, Bachi A, Rubartelli A Agresti A, Bianchi ME: Monocytic cells hyperacetylate chromatin protein HMGB1 to redirect it towards secretion. EMBO J 2003, 22:5551-5560.

31. Yang H, Ochani M, Li J, Qiang X, Tanovic M, Harris HE, Susarla SM, Ulloa L, Wang H, DiRaimo R, Czura CJ, Wang H, Roth J, Warren HS, Fink MP, Fenton MJ, Andersson U, Tracey KJ: Reversing established sepsis with antagonists of endogenous high-mobility group box 1. Proc Natl Acad Sci USA 2004, 101:296-301.

32. Ombrellino M, Wang $H$, Ajemian MS, Talhouk A, Scher LA, Friedman SG, Tracey KJ: Increased serum concentrations of high-mobility group protein 1 in haemorrhagic shock. Lancet 1999, 354:1446-1447.

33. Wang H, Vishnubhakat JM, Bloom O, Zhang M, Ombrellino M, Sama A, Tracey KJ: Proinflammatory cytokines (tumor necrosis factor and interleukin 1) stimulate release of high mobility group protein-1 by pituicytes. Surgery 1999, 126:389-392.

34. Huttunen HJ, Fages $C$, Rauvala $\mathrm{H}$ : Receptor for advanced glycation end products (RAGE)-mediated neurite outgrowth and activation of NF-kB require the cytoplasmic domain of the receptor but different downstream signaling pathways. J Biol Chem 1999, 274:19919-19924.

35. Taguchi A, Blood DC, del Toro G, Canet A, Lee DC, Qu W, Tanji N, Lu Y, Lalla E, Fu C, Hofmann MA, Kislinger T, Ingram M, Lu A, Tanaka H, Hori O, Ogawa S, Stern DM, Schmidt AM: Blockade of RAGE amphoterin signalling suppresses tumour growth and metastases. Nature 2000, 405:354-360. 
36. Park JS, Arcaroli J, Yum HK, Yang H, Wang H, Yang KY, Choe KH, Strassheim D, Pitts TM, Tracey KJ, Abraham E: Activation of gene expression in human neutrophils by high mobility group box 1 protein. Am J Physiol Cell Physiol 2003, 284:C870-C879.

37. Schmidt AM, Yan SD, Yan SF, Stern DM: The biology of the receptor for advanced glycation end products and its ligands. Biochim Biophys Acta 2000, 1498:99-111.

38. Huttunen HJ, Rauvala H: Amphoterin as an extracellular regulator of cell motility: from discovery to disease. J Int Med 2004, 255:351-366.

39. Park JS, Svetkauskaite D, He Q, Kim JY, Strassheim D, Ishizaka A, Abraham E: Involvement of Toll-like receptors 2 and 4 in cellular activation by high mobility group box 1 protein. J Biol Chem 2004, 279:7370-7377.

40. Tsung A, Sahai R, Tanaka H, Nakao A, Fink MP, Lotze MT, Yang H, Li J, Tracey KJ, Geller DA, Billiar TR: The nuclear factor HMGB1 mediates hepatic injury after murine liver ischemia-reperfusion. J Exp Med 2005, 201:1135-1143.

41. Muhammad S, Barakat W, Stoyanov S, Murikinati S, Yang H, Tracey K, Bendszus M, Rossetti G, Nawroth PP, Bierhaus A, Schwaninger M: The HMGB1 receptor RAGE mediates ischemic brain damage. J Neurosci 2008, 28:12023-12031.

42. Sobey CG, Faraci FM: Subarachnoid haemorrhage: what happens to the cerebral arteries? Clin Exp Pharmacol Physiol 1998, 25:867-876.

43. Cook DA: Mechanisms of cerebral vasospasm in subarachnoid haemorrhage. Pharmacol Ther 1995, 66:259-284

44. Hansen-Schwartz J, Vajkoczy P, Macdonald RL, Pluta RM, Zhang JH: Cerebral vasospasm: looking beyond vasoconstriction. Trends Pharmacol Sci 2007, 28:252-256.

45. Pluta RM, Hansen-Schwartz J, Dreier J, Vajkoczy P, Macdonald RL, Nishizawa S, Kasuya H, Wellman G, Keller E, Zauner A, Dorsch N, Clark J, Ono S, Kiris T, Leroux P, Zhang JH: Cerebral vasospasm following subarachnoid hemorrhage: time for a new world of thought. Neurol Res 2009, 31:151-158.

46. Sabri M, Kawashima A, Ai J, Macdonald RL: Neuronal and astrocytic apoptosis after subarachnoid hemorrhage: a possible cause for poor prognosis. Brain Res 2008, 1238:163-171.

47. Vergouwen MD, Vermeulen M, Coert BA, Stroes ES, Roos YB: Microthrombosis after aneurysmal subarachnoid hemorrhage: an additional explanation for delayed cerebral ischemia. J Cereb Blood Flow Metab 2008, 28:1761-1770.

48. Wellman GC: Ion channels and calcium signaling in cerebral arteries following subarachnoid hemorrhage. Neurol Res 2006, 28:690-702.

49. Skrha J Jr, Kalousová M, Svarcová J, Muravská A, Kvasnička J, Landová L, Zima T, Skrha J: Relationship of soluble RAGE and RAGE ligands HMGB1 and EN-RAGE to endothelial dysfunction in Type 1 and Type 2 diabetes mellitus. Exp Clin Endocrinol Diabetes 2012, 120:277-281.

50. Haraba R, Uyy E, Suica VI, Ivan L, Antohe F: Fluvastatin reduces the high mobility group box 1 protein expression in hyperlipidemia. Int J Cardiol 2011, 150:105-107.

51. Tang D, Kang R, Zeh HJ 3rd, Lotze MT: High-mobility group box 1, oxidative stress, and disease. Antioxid Redox Signal 2011, 14:1315-1335.

52. Ding HS, Yang J: High mobility group box-1 and cardiovascular diseases. Saudi Med J 2010, 31:486-489.

doi:10.1186/1742-2094-9-194

Cite this article as: Zhu et al:: Relationship between plasma high mobility group box-1 protein levels and clinical outcomes of aneurysmal subarachnoid hemorrhage. Journal of Neuroinflammation 2012 9:194.

\section{Submit your next manuscript to BioMed Central and take full advantage of:}

- Convenient online submission

- Thorough peer review

- No space constraints or color figure charges

- Immediate publication on acceptance

- Inclusion in PubMed, CAS, Scopus and Google Scholar

- Research which is freely available for redistribution 